\title{
Study on the Conflict and Integration of Sales Channels
}

\author{
Di Kang ${ }^{1, a}$ \\ ${ }^{1}$ Department of Information Management, Hainan College of Software Technology, Qionghai, \\ Hainan, China, 571400 \\ ${ }^{a}$ email
}

Keywords: Market Economy, Sales Channel and Conflict, Integration

\begin{abstract}
Changes in the economy, technology, competition, culture, external environment to the traditional marketing channel model had a huge impact, but also to promote the development and marketing channel model innovation. In the global economy, fierce competition in the consumer maturity to a certain extent today, the traditional marketing channel model in terms of efficiency, cost and controllability disadvantages have become increasingly prominent, one had been overlooked elements of a marketing mix marketing people began to channel attention, and winning the market become a strategic competitive advantage. In the new economic era, the traditional product-centric marketing channels is the customer-centric marketing network excessive, and the development of science and technology, particularly the Internet, electronic communications technology development has provided the conditions for this change. Channel innovation and integration will become a major issue in the 21st century market development stage Chinese enterprises are facing.
\end{abstract}

\section{Introduction}

In the modern market environment, in the face of increasingly fierce market competition, manufacturers of traditional marketing channel architecture is unreasonable, a single type, do not communicate between the management and scientific channels, lack of cooperation and other issues gradually revealed, seriously affecting economic efficiency and improve the competitiveness of enterprises, while companies in the market competition in order to win, you have the traditional marketing channel system innovation, enterprise-specific characteristics according to the needs of the target market of a systematic analysis of marketing channels, the implementation of channel integration.

Marketing channel integration refers to all enterprise marketing channel as a system, the use of systems theory and methods to be integrated, thereby to create enterprise core competencies and competitive advantage. It integrated into the center, and strive to systematic management, emphasizing the coordination and harmonization, focusing on large-scale and modernization. Integrated marketing channels, there are two basic types of integration between marketing channel integration in the marketing channels. Marketing Channel integration refers to multi-channel marketing system for each marketing channel independently undertake its services in the marketing function, the formation of a separate sales channel and product sales, in order to increase market coverage and increase product sales. Each marketing channel integration between marketing channels are independent of each other. Within the marketing channel integration refers to the marketing process sales tasks eleven each assigned to complete the task can be better at a lower cost marketing channels, marketing channels are combined to form an optimum sales channels to achieve sales goals .

Traditionally, companies just use a single channel toward the single market. Today, as the business segments and increasing use of marketing channels, companies can create two or more marketing channels to reach one or more market segments. By using a variety of channels, marketing channel integration, companies can increase market coverage to better meet customer needs, reduce distribution costs, increase product sales. However, using a variety of marketing channels, will inevitably produce conflict and control issues. Therefore, the integration of research marketing channels, on the one hand you want to play the advantages of enterprise multi-channel 
marketing system, on the other hand to make to minimize conflicts and maximize cooperation.

Thus, changes in the market environment for the management and distribution channel model put forward new requirements, innovation and integration of distribution channels has become a major strategic issue in the 21st century a new stage of market development of Chinese enterprises are facing.

\section{Model of traditional marketing channels}

Because traditional marketing channels by independent producers, wholesalers and retailers, as each member is a separate corporate entities or individuals seeking to maximize their own profits. Thus, in the conventional channels, just as an American scholar door McConnell pointed out: In the fragmented network of loosely arranged manufacturers, wholesalers and retailers, they are bargaining with each other while maintaining distance sales negotiations conditions, and other aspects of autonomy to act. Here each channel members pursue personal gain maximization. While maximizing the benefits of this individual channel members will inevitably lead to conflict, and the results due to the conflict but lead to increased transaction costs, earnings damaged. Therefore, we must design an effective system of innovation in the channel system to ensure the channel members to determine how to benefit in economic activities, as well as how to compensate the damage how to improve circulation efficiency and reduce transaction costs.

Vertical marketing system to implement the vertical integration of the substance of the transaction is that the market internalization, reduce transaction costs, by manufacturers, wholesalers cooperation, joint production and sales, purchases, control, and access to economic benefits in the other areas. At the same time due to increased barriers to entry, competitors from entering the high cost of integration channels takes to protect the interests of channel members. Foreign long-term implementation of the agency so that operators and manufacturers in the form of agreements Contracts enable businesses to form a long-term stable relationship between production and marketing, to facilitate the manufacturers to reduce transaction costs to gather information to develop new markets spent. In the internal channels by establishing a channel leader to manage, control and coordinate the interests of each of the channel members to avoid collapse of the channel resulting in higher transaction costs. The interests of all members of the marketing channel system is the most evident in the price, the price structure is a dynamic mechanism channels the main part and the most sensitive part, which determines the allocation of the share of profits manufacturers, wholesalers and retailers. This difference is determined by each channel member in the channel status and power. Advantage determines the difference between the power producers, wholesalers and retailers pricing. Vertical marketing system of rights may be governed by the manufacturer to be dominated by the wholesalers or retailers.

Level marketing system refers to a number of companies within the same level of marketing channels to take a lateral joint approach, joint venture or cooperation open up new marketing opportunities, to form a new channel system. This joint venture is mainly due to expectations of greater synergies, or due to the accumulation of individual companies unable to conduct business alone must have huge capital, advanced technology, production equipment and marketing facilities, or because the risk is too reluctant separate adventures. Joint action between companies may be temporary, and may be permanent, you can also create a specialized company. Marketing experts Adler called it symbiotic marketing, such as: Agricultural Bank of China branch in Shanghai Friendship South Mall site sales offices and ATMs, the bank reduced the operational start-up costs, friendship South Mall was to provide customers with in-store facilitate access to bank money.

Multi-channel marketing system, also known as hybrid channel marketing system, the enterprises to establish two or more marketing channels to reach one or more customer segments. By adding more channels, companies can get at least three benefits: increase market coverage, reduce distribution costs and tend to be more customer-oriented services. 


\section{Marketing Channel Integration Management}

Before the opening of the new channels, companies must existing traditional channels thorough integration of home appliance industry, for example, the domestic color TV manufacturers generally adopt marketing model there are two: one is a centralized system, the entire marketing network establish top-down by the manufacturers, their grasp, the other by the agents blanket. Before too fierce market competition, the two marketing models often great disadvantages. Although the former to avoid all kinds of interference large, but manufacturers building sales network is not consistent with the principles of social division of labor, the greater problem is self-built network will allow rising marketing costs, cash flow difficulties, the manufacturers eventually overwhelmed. With the channel's maturity, self-built appliance business marketing network division sales model is increasingly under attack, large commercial enterprises and super chain stores due to their operating characteristics of social resources, sales channels and products in the professional production and marketing has often self-built networks can not match advantage. Haier's marketing model is a typical centralized system, not through the intermediate links, but directly at the terminal distributor. But Haier Here, the terminal is different from the terminal auto dealers in the above sense that Haier terminal distributor largely refers to his own and set up, under the corporate structure of its dealers, rather than the outside in its corporate structure and exist independently in circulation in the area of the terminal retail dealers. This is the Haier stubborn side, that is too much focus on their sales terminal construction and maintenance, and lack of circulation for the existence of large retail dealers attention and use.

Before purchasing behavior, since there is a strong asymmetry of information between businesses and consumers, customers understand the product knowledge is particularly urgent, such as what is the frequency, what is continuously variable, especially when comparing similar products hope to understand these professional terms what it means for their own customers, but many companies do this very place, relying on store sales staff to explain the scene and very difficult to maintain a standard level. Enterprise through the website and Cal1Center for customers purchasing product knowledge to provide adequate pre-sale services, such as product Tips section of the site, a list of relevant product knowledge to customers should know before buying the product information services. Customers in the sale of household appliances also need to help service products, since the various problems encountered in the use of the product, product specification is not intended to be exhaustive (product specification is difficult to maintain long-term), then we need to build a customer a encounter problems you can immediately go to see the place, the corporate website product FAQs (FAQ) is a good way to solve this problem, not only allows customers to find the answers, also allows customers to take the initiative to ask questions and to question the accumulation of customers The answer, constantly enrich the problem library. Deeper than the FAQ's approach to customer service is the customer community, customers take advantage of the community to achieve mutual exchange of experiences and discuss methods, such as some software companies website and automobile club's website.

Modern enterprise for its own long-term development, more attention to customer lifetime value. Customer relationship management, customer distinction grades, to provide personalized service for a variety of customers, and establish a one to one marketing model is an effective means of attracting customers. The call center has become the gateway to business and customer contact, for enterprises, call centers capable of converting potential customers into customers, convert customers into loyal customers, which is the key point of the enterprise customer-centric strategy. For this reason many companies have or plan to establish call centers to adapt to their needs, and this application call center customer relationship management, it has been transformed from the previous passive to proactive customer service center contact center. For the appliance industry, service centers, and technical support from functioning at this moment is to provide service and technical support, therefore, to focus on its internal management and customer call center data mining efforts to improve call center efficiency, transition to the call center knowledge, and gradually make the call center from a cost center into a profit center in expanding business scope of 
services and improve service quality at the same time, through this channel and to keep abreast of changes in customer demand, the real call center become an established relationship with the customer to maintain and develop customer and always grasp the customer demand for strategic weapons.

\section{Conclusion}

In the modern market environment, in the face of increasingly fierce market competition, manufacturers of traditional marketing channel architecture is unreasonable, a single type, do not communicate between the management and scientific channels, lack of cooperation and other issues gradually revealed, seriously affecting economic efficiency and improve the competitiveness of enterprises, while companies in the market competition in order to win, you have the traditional marketing channel system innovation, enterprise-specific characteristics according to the needs of the target market of a systematic analysis of marketing channels, the implementation of channel integration.

\section{References}

[1] Kabadayi, S., Choosing the right multiple channel system to minimize transaction costs, Industrial Marketing Management (2011),doi:10.1016/j.indmarman.2011.02.002

[2] Philip Kotleretal.Marketing Move: A New Approach to Profits, Growth, and Renewal [M]. Harvard Business School Publishing Corporation,2002.

[3] Duncan,T. \&Moriarty. S..Driving BrandValue [M].McGraw-Hill,1999.

[4] Peter F. Drucker. Management Challenges for the 21st Century[M].Big Apple Tuttlen Mori Agency Inc,1999. 